\title{
Biopsy of Temporal Artery
}

National Cancer Institute

\section{Source}

National Cancer Institute. Biopsy of Temporal Artery. NCI Thesaurus. Code C51932.

Removal of a portion of the temporal artery for microscopic examination. 